\title{
Uma experiência inclusiva e formadora de crianças e jovens
}

Rosiane Limaverde

O relato trata da experiência da Fundação Casa Grande - Memorial do Homem Kariri, localizada em Nova Olinda, no Vale do Cariri, Ceará. O espaço, que atualmente é uma Escola de Comunicação e Cultura, oferece a crianças e jovens a oportunidade de desenvolverem diversas atividades culturais, como a produção de documentários e programas de rádio e TV, atividades musicais e teatrais, dentre outras. Além das atividades de formação e protagonismo infantojuvenil, a Fundação Casa Grande desempenha um importante papel na transmissão e, portanto, valorização do patrimônio cultural local, tendo se transformado em pólo turístico, atraindo milhares de visitantes anualmente e contribuindo para o desenvolvimento econômico regional.

Palavras-chave: Fundação Casa Grande; Memorial do Homem Kariri; produção audiovisual; patrimônio cultural local; Vale do Cariri (CE); desenvolvimento local 


\section{An experience to include and educate children and young people}

Rosiane Limaverde

This report is about the experience by Fundação Casa Grande - Memorial do Homem Kariri, located in Nova Olinda, in Vale do Cariri, Ceará, Brazil. That space, which is currently a Communication and Culture School, provides children and young people with the opportunity of performing several cultural activities, such as producing documentaries and radio and TV shows, musical and theater activities, among others. Besides activities for youth education and theater, Fundação Casa Grande plays an important role in transmitting and, as consequence, adding value to the local cultural patrimony, and has turned out to be a touristic pole, attracting thousands of visitors every year and contributing to the regional economic development.

key words: Fundação Casa Grande; Memorial do Homem Kariri; audiovisual production; local cultural patrimony; Vale do Cariri (CE); local development 


\title{
Uma experiência inclusiva e formadora de crianças e jovens
}

\author{
ROSIANE LIMAVERDE*
}

A Fundação Casa Grande - Memorial do Homem Kariri ${ }^{1}$ surgiu como um projeto de museu idealizado por Alemberg Quindins e Rosiane Limaverde. Atualmente, é uma Escola de Comunicação e Cultura plantada no Vale do Cariri $^{2}$ cearense, com uma vasta produção cultural elaborada por crianças e adolescentes: programas de rádio e TV, atividades musicais e teatrais, produção de documentários, administração e programação do museu.

Fundada em 1992, a Casa Grande é um modelo de entidade que promove a inclusão social e o protagonismo infanto-juvenil. Mudou a realidade de Nova Olinda ${ }^{3}$, cidade com pouco mais de 12 mil habitantes.

\section{Construção de identidade, patrimônio cultural e cidadania}

Pensar em patrimônio cultural é refletir sobre transcendência, algo que transcende o presente, na medida em que esse conceito engloba as gentes, os costumes, os sabores e os saberes. Patrimônio cultural não se resume às edificações históricas, aos sítios de pedra e cal. 0 patrimônio cultural deve ser entendido não como um dado estático apenas, pois não é só o concreto, e sim uma construção resultante de um processo no qual se atribuem significados e sentidos - reconhecê-lo assim é avançar no entendimento da sua dimensão política, econômica, ecológica e social.

Foi do material de pedra e cal e do intangível da história - fatos, memória, lendas e mitos - que, em 1992, por meio da iniciativa de um jovem casal de músicos Alemberg Quindins e Rosiane Limaverde -, uma comunidade se permitiu restaurar um antigo casarão azul: ele

\footnotetext{
* Rosiane Limaverde é Presidente do Conselho Científico da Fundação Casa Grande - Memorial do Homem Kariri.
}

foi marco do século XVII, entre a história colonial dos vaqueiros do sertão nordestino e as terras indígenas dos Kariri, na porta de entrada do vale da Chapada do Araripe, região do Cariri, Nova Olinda, Ceará.

A Casa Grande, como hoje é conhecida, foi restaurada para guardar em acervo, a cultura do povo Kariri, a partir da criação da ONG Fundação Casa Grande - Memorial do Homem Kariri, hoje um pontão de cultura disseminador de tecnologias de gestão cultural para jovens do Brasil e do mundo.

Desde o início de sua criação, percebeu-se a iminente necessidade de acolher as crianças e os jovens da pequena cidade de Nova Olinda, de 12 mil habitantes. Eles enfrentavam a falta de perspectiva de vida e a necessidade de inclusão sócio-cultural, vivendo à margem da sociedade brasileira, sem ter acesso às informações, ao conhecimento de qualidade e a uma formação humana integral.

No sertão do Brasil, ainda são poucos os incentivos ao desenvolvimento da autoestima da criança e do jovem, do autoconhecimento, como também da construção de identidade, patrimônio cultural e cidadania. Essa realidade está provocando nas novas gerações do interior do nosso país um grave empobrecimento cultural, consumo de drogas, prostituição, violência e subemprego.

O desafio da Fundação Casa Grande foi sistematizar uma ação educativa que proporcionasse a esses meninos e meninas do interior do Brasil ferramentas formadoras para a ampliação do repertório cultural, trazendo o "mundo ao sertão". Tudo isso foi possível pelo acesso e internalização de novos saberes e conteúdos de qualidade em assuntos como: memória, patrimônio, cultura, arqueologia, mitologia, comunicação, meio ambiente, arte e cidadania.

O percurso inicial deu-se por meio da pesquisa sobre 
os sons, os mitos, as lendas e o homem antigo que habitou a região, promovendo a criação de um museu de referência sobre a pré-história regional - o Memorial do Homem Kariri. Queríamos acolher todo o acervo arqueológico que populares haviam descoberto casualmente e nos doado. Assim, surgiu o primeiro Programa da Fundação: o Programa de Memória.

As crianças chegaram ao espaço da Casa Grande e se identificaram com as lendas e o acervo pré-histórico dos primeiros habitantes da Chapada do Araripe. Com o tempo, a novidade do Museu foi dando lugar ao sentimento de pertença a esse espaço, um ambiente onde os mitos e lendas contados por seus avôs estavam personificados e justificados nas machadinhas de pedra dos antigos parentes indígenas ali encontrados.

Essas crianças foram os primeiros guias mirins do $\mathrm{Mu}$ seu e hoje, passados 17 anos, são os jovens que formam o Conselho Cultural da Fundação Casa Grande e que repassam para os mais novos e para quem ali passa a tecnologia da gestão cultural. Essa tecnologia também já está sendo levada por esses jovens gestores até o mundo, formando crianças e jovens em Moçambique e Angola, na África, e em Portugal, Itália e Alemanha, na Europa.

\section{O Homem Kariri renasceu em cada pessoa}

\section{A Fundação Casa Grande atende anualmente cerca de} 25 mil visitantes, e todo esse potencial turístico tem proporcionado ao Município de Nova Olinda a alternativa de desenvolvimento econômico e social através do Turismo Social de Base Comunitária, gerando emprego e renda para as famílias.

Em 2008, o Município recebeu do Ministério do Turismo a categoria nacional de Município indutor do turismo, para a implementação de ações de desenvolvimento regional através do turismo. A comunidade também teve sua identidade e autoestima valorizadas pelos seus mais dignos representantes - as crianças - e apreenderam o significado do Memorial do Homem Kariri como parte de suas vidas.

No cotidiano da Fundação Casa Grande, o prazer em ouvir e compor músicas, trocar informações, desenhar, criar personagens e histórias em quadrinhos, produzirvídeos no estúdio de TV, gerenciar espetáculos num teatro com capacidade para 200 pessoas e manter uma rádio funcionando das 5 às $22 \mathrm{~h}$, diariamente, vêm transformando crianças e jovens em gestores culturais.
As atividades realizadas estão compreendidas em cinco programas: Memória, Artes, Comunicação, Turismo, Meio Ambiente e Esporte. Esses programas estão apoiados em dois pilares: conteúdo e produção, que sintetizam a base dos saberes e fazeres da Fundação Casa Grande.

Todos os projetos desenvolvidos e em desenvolvimento na Fundação pertencem aos laboratórios de "produção" e partem de uma "leitura do mundo": o mundo do sertão do Cariri e do verde vale da Chapada do Araripe. Partem do fazer cotidiano que integra teoria e prática. São os laboratórios de conteúdo que servem de instrumentalização e favorecem uma melhor execução de planos nos laboratórios de produção.

Ao se apropriar de uma paisagem natural como a Chapada do Araripe, catalisadora de povos e culturas desde a pré-história, ao mesmo tempo em que se apropriam de novas tecnologias como o rádio, a TV e a internet, as crianças e jovens da Fundação Casa Grande se dão conta da relação do homem com a natureza onde a cultura é o agente, a área natural o meio e a paisagem cultural o resultado.

NOTAS

1 Para saber mais sobre os índios Kariri, consultar: http://opovo.uol.com.br/opovo/ceara/752496.html; http://pib.socioambiental.org/en/noticias?id=63483; http://www.overmundo.com.br/blogs/pesquisadora-descobre-tribo; http://pt.wikipedia.org/wiki/Cariris;

2 Região do Cariri

A Região do Cariri, que abrange a atuação do Escritório de Desenvolvimento Regional, é composta pelos municípios cearenses de: Altaneira, Barbalha, Caririaçu, Crato, Farias Brito, Granjeiro, Jardim, Juazeiro do Norte, Missão Velha, Nova Olinda, Porteiras e Santana do Cariri.

http://www.cariri.org.br/aregiao.jsp

3 Nova Olinda

Nova Olinda é uma cidade e um município do Estado do Ceará. Localiza-se na microrregião do Cariri, mesorregião do Sul Cearense, região metropolitana do Cariri. O município tem cerca de 13 mil habitantes e $291 \mathrm{~km}^{2}$. Foi criado em 1957. Está a 537 km de Fortaleza. 


\title{
Um novo chão de fábrica
}

\author{
Carlos Gustavo Yoda *
}

\begin{abstract}
A fábrica do futuro deverá ser aquele lugar em que o homem aprenderá, juntamente com os aparelhos eletrônicos, o quê, para quê e como colocar as coisas em uso. E os futuros arquitetos fabris terão de projetar escolas ou, em termos clássicos, academias, templos de sabedoria. Como deverá ser o aspecto desses templos, se estarão materialmente assentados no chão, se flutuarão como objetos semimateriais, se serão quase totalmente imateriais, é uma questão secundária.
\end{abstract}

VILÉM FLUSSER

O mundo codificado - Por uma filosofia do Design e da Comunicação. São Paulo: Cosac Naify, 2007.

A cidade de Cataguases, situada na Zona da Mata mineira, tem pouco mais de 70 mil habitantes e está a 280 quilômetros de Belo Horizonte e a 240, da cidade do Rio de Janeiro. Apesar do distanciamento geográfico desses centros, a efervescência de artistas e empreendedores locais fez do pequeno município um laboratório do modernismo brasileiro e também um cenário para o início do cinema nacional com Humberto Mauro.

Essa rica produção cultural, que consagrou o município como referência no Brasil e no exterior, teve origem no pioneirismo da industrialização da cidade. Desde 1905, as indústrias têxtil e de energia elétrica são os grandes promotores e financiadores da cultura local. Até hoje, esse é um fator fundamental para a presença de fundações e institutos ligados a programas corporativos de responsabilidade social empresarial.

O legado histórico e o contexto atual motivaram, em 2003, o início de um amplo programa de Cultura e Desenvolvimento Local, articulado a partir de uma rede de cooperação horizontal formada por lideranças sociais, cul-

\footnotetext{
* Carlos Gustavo Yoda é repórter especializado em políticas culturais. Atuou na Agência Carta Maior e em Cultura e Mercado, entre outros veículos, e presta serviços de consultoria, formação e planejamento em comunicação digital.
}

turais e empresariais. Um processo inspirado na Agenda 21 da Cultura, com foco no audiovisual, nas novas tecnologias e no desenvolvimento de políticas públicas na cidade e região.

É nesse momento que surge a Fábrica do Futuro - Incubadora Cultural do Audiovisual e das Novas Tecnologias, que tem como missão desenvolver formas diversas e colaborativas de criação, produção e difusão audiovisual. Inaugurada em 2005 como um Ponto de Cultura do Programa Cultura Viva, do Ministério da Cultura, a Fábrica desenvolve suas ações por meio de tecnologias inovadoras aplicadas à comunicação.

Em quatro anos, a incubadora cultural formou uma equipe multidisciplinar com mais de 30 pessoas profissionalizadas, dentre técnicos em vídeo, áudio e multimídias, músicos, fotógrafos, desenhistas, designers, programadores de web, jornalistas, produtores e gestores culturais. Para o gestor cultural da Fábrica do Futuro, Cesar Piva, foi essa equipe que possibilitou um dos passos mais importantes na trajetória da Fábrica: a implantação da plataforma eletrônica da Fábrica do Futuro na Internet. "Nosso portal é mais do que um espaço de difusão e comunicação é, sobretudo, nosso ambiente de trabalho colaborativo e espaço de aprendizado, formação e qualificação profissional em rede", afirma Cesar.

A partir de 2007 a Fábrica passou a contar com duas unidades: a primeira, concebida como espaço de gestão e produção; e a segunda, como um albergue com capacidade para receber doze pessoas. Foram condições necessárias para atravessar as fronteiras de Minas Gerais e se conectar em âmbito nacional e internacional, seja por meio dos pontos de cultura em todo o País, ou de redes de cooperação com as quais atua nos países de língua portuguesa e ibero-americanos. 

e eventos, como uma das melhores oportunidades para a formação dos jovens. É Kaká quem confirma:

O que fica de mais importante para quem passa pela Fábrica é a formação humana que temos. Aprendemos fazendo. Ninguém mais precisa trabalhar com o que não gosta. Na Fábrica, aprendemos essas coisas que não são ensinadas nas escolas.

\section{Artur de Leos}

Já o fotógrafo paulistano Artur de Leos deixou o maior centro econômico do País e embarcou para Cataguases a fim de participar da primeira Residência Criativa do Audiovisual - RECRIA, que reuniu as cidades de Cataguases, Ouro Preto e Brumadinho. Ele relata:

Com um grupo de 15 jovens, criamos micronarrativas próprias para difusão em telefonia móvel, na qual possibilitamos aos visitantes dessas cidades, receberem esse trabalho em seu celular e ampliar sua visão sobre o barroco, o modernismo e arte contemporânea.

\section{Gustavo Baldez e David Azevedo}

O jovem Gustavo Baldez que, de eletricista na Prefeitura local, virou web designer e coordenador do núcleo de comunicação na Fábrica do Futuro, conta:

Com o Fundo Estadual de Cultura, fizemos uma experiência inédita de WebTV envolvendo cidades do interior de Minas. Com a TV Brasil e a TV Minas, já produzimos com os pontos de cultura em âmbito regional e nacional. Estamos produzindo conteúdo cultural para celular. Existe um mercado novo surgindo, no qual a colaboração é a chave.

Outra ação que ele destaca é o Programa VIVO LAB. A partir de 2009, o canal mobiliza uma rede colaborativa de cultura na Internet e nas mídias móveis. Em parceria com a Vivo, a Fábrica do Futuro é responsável pela ativação da rede: realiza residências criativas presenciais e virtuais e organiza coletivos de jovens para cobertura de projetos e eventos, por meio da Agencia Multimídia de Webvisão AMW. David Azevedo, um jovem programador do núcleo de tecnologia da Fábrica do Futuro, explica:

Aprendemos na prática com o nosso portal e hoje desenvolvemos tecnologia e novas ferramentas que, além de agregar os conteúdos produzidos, dão a sustentação para as interfaces entre projetos, pessoas, conceitos e eventos da rede no portal Vivo Lab.

\section{Cláudio Santos}

Para o designer Cláudio Santos, da Voltz de Belo Horizonte e parceiro da Fábrica do Futuro, o tipo de profissional que a Fábrica está formando é muito diferente dos que saem diplomados pelas faculdades:

\footnotetext{
A demanda é muito grande para um profissional com visão interdisciplinar. Eu costumo contratar na minha empresa o cara que é músico, blogueiro, programador, que tira foto e entende de audiovisual.
}

Antropofagia, Educação Colaborativa e Acessibilidade.

Cataguases não conta com uma rede qualificada de ensino superior e técnico na área da cultura e das novas tecnologias. Foi para suprir essa carência de formação e certificação que a Fábrica do Futuro buscou em 2007 uma parceria com o LABMIDIA da Universidade Federal de Minas Gerais - UFMG. Essa ação ganhou potencia com novas perspectivas para a formação e produção à distância e resultou no lançamento do Espaço de Aprendizado em Rede - e.AR, no portal da Fábrica do Futuro.

Regina Mota, professora e pesquisadora da UFMG, colaborou na concepção do espaço de formação e afirma que um dos roteiros de aprendizagem propostos é baseado no manifesto antropofágico. Para ela, a leitura sobre o modernismo nos tempos atuais é fundamental para refletir acerca do momento que estamos atravessando. Regina percebe três relações entre características do ritual Tupinambá com os trabalhos da Fábrica:

0 caráter crítico, a apologia à diferença, que representa o reconhecimento, e a atitude anti-hierárquica. A cultura do remix e a cultura hacker têm tudo a ver com isso. É a barbárie tecnizada. 0 selvagem se apropria das tecnologias da civilização, mas não se torna um civilizado. Ele vira um bárbaro tecnizado e passa a ser mais o outro e ele mesmo. 
Gustavo Jardim, documentarista da DuRolo Filmes, de Belo Horizonte, e parceiro da Fábrica do Futuro, destaca o e.AR como promotor de uma investigação da arte com a perspectiva do outro:

O e.AR é um salto de diferença em relação ao EAD. É o aprendizado em construção colaborativa. Os roteiros são construídos derrubando a ideia de aluno. Todos são colaboradores.

\section{Cesar Piva pontua:}

O lugar da formação se desloca no ar e pula os muros da academia. O Festival de Ver e Fazer Filmes caminha também nesse sentido.

Realizado em parceria com a Fundação Ormeo Junqueira Botelho, sua primeira edição reuniu, em 2008, alunos de três universidades; uma portuguesa e duas brasileiras. Todos envolvidos na produção de três filmes de curta metragem, com a participação de mais de 200 pessoas de Cataguases. O Festival deve entrar para agenda permanente de grandes eventos na cidade.

Para possibilitar ainda mais a formação de público e ampliar o repertório cultural da região, sobretudo da população local, foi criado em parceria com o Instituto Votorantin, o Projeto TELA VIVA.

Segundo Karina Freitas, uma das produtoras do projeto:

A unidade móvel de cinema leva o acesso à produção audiovisual brasileira, mobiliza as comunidades para se reconhecerem e produzirem suas próprias histórias. Mas, principalmente, contribui para recuperar o espaço público, um exercício de cidadania.

\section{Economia Criativa da Cultura e Sustentabilidade}

Em um mercado permeado por cobrança de resultados e balanços de produção, divisão e precarização do trabalho, a Fábrica do Futuro optou por percorrer outros caminhos bem distintos, comenta Erick Krulikowski, gestor de projetos especiais da Fábrica do Futuro:

Buscamos promover uma experiência de gestão de processos e trabalho colaborativo, com geração de oportunidades, empreendimentos e distribuição de riquezas. Reunimos essa experiência de gestão às novas tecnologias, explorando ao máximo a rede produtiva do audiovisual, com a pesquisa, experimentação, formação, criação, produção, distribuição, difusão e formação de público, de maneira a estruturar a economia criativa ligada a esse setor na região.

E foi com o objetivo de ampliar o impacto da Fábrica do Futuro que foi criado o Projeto ANIMAPARQUE - Pólo de Audiovisual, Animação e Mídias Digitais. A intenção é construir, em Cataguases, um centro de excelência internacional para criação de conteúdos audiovisuais em rede, com foco na animação e nas mídias digitais, sobretudo, para o público infanto-juvenil. O Pólo funcionará com base em uma escola, uma incubadora e uma central de produção. 0 projeto, lançado em julho de $2009 \mathrm{e}$ com inauguração prevista para 2011, está em fase acelerada de elaboração de planos de sustentabilidade, modelo de negócios, gestão, formação, conceito arquitetônico e impacto urbano.

Cesar Piva conclui:

Será um centro internacional de formação e produção bem diferenciado, com outros caminhos para mercado, trabalho e renda. Desse processo, surgirão novos modelos de empresas, coletivos, cooperativas, redes, ONGs e projetos. Não devemos repetir a escola e a indústria do século passado. É outro chão de fábrica, em uma sociedade em rede. Estamos falando de cultura, associada à comunicação e à apropriação social das novas tecnologias. Esse é nosso mais ousado sonho; e vamos realizá-lo! 